\title{
LOS DIOSES-DIAS PARLANTES: HACIA UN SISTEMA DE ADIVINACIÓN EN LOS ALMANAQUES DE LOS CÓDICES MAYAS ${ }^{1}$
}

\author{
Laura Elena Sotelo Santos
}

Centro de Estudios Mayas

\begin{abstract}
Aвsтист: The purpose of this paper is to present a new approach to the use and applications of the 260th day Almanacs, as they were written in the precolombian Mayan codices, through the method actually employed by kicheo'ob, and ixilo'ob, shamans, in their use and prognostication for ruling their lives. Many scholars have studied both systems, but, in this paper, they are combined to prove that the old systems is still alive, and that it is only by the understanding of both systems, developed through knowledge of epigraphic, historic and ethnographic information, that it is possible to have a better understanding about the way in wich precolombian priests used their manuscripts.
\end{abstract}

Resumen: En este artículo se propone que el sistema de adivinación empleado por los sacerdotes mayas contemporáneos, llamados "contadores de los días", es esencialmente el mismo que está representado en los almanaques de los códices mayas. A través de la epigrafia, la historia y la etnología se comparan ejemplos de las prácticas adivinatorias entre quichés e ixiles con los almanaques de 260 días del Codice Madrid y se sugieren algunas ideas para realizar futuras investigaciones.

Los códices mayas son muestra de la fe de un pueblo; en ellos está plasmada una serie de creencias que estuvieron vivas y que formaban parte no sólo del pensamiento, sino también de los sentimientos de la comunidad. En ellos se encontraban las respuestas a muchas de las preguntas que los antiguos hombres mayas se hacían: ¿cuándo debo sembrar?, ¿habrá buena cacería de venados?, ¿tendré hijos?, ¿lloverá poco?, ¿es éste el momento oportuno para casarme?

Esas preguntas estaban dirigidas a los dioses -quienes según el pensamiento maya controlaban todos los aspectos de la realidad-, lo que necesariamente implica que es posible estar en contacto con ellos. Por esto, hombres y mujeres acudian al especialista, al ah kin, quien consultaba en los códices el calendario de 260 dias, y señalaba cuál era la voluntad de los dioses y los medios y momentos adecuados para realizar los ritos y las ceremonias pertinentes.

$\mathrm{Si}$ el universo, que es un todo ordenado y estructurado, es obra divina, el estar en contacto con los dioses es también comprender la realidad. Sin embargo, en el pensamiento religioso, el lenguaje de los dioses generalmente no está al alcance de la mayoría de los hombres; entenderlo supone un aprendizaje largo y dificil, peligroso, por lo que los especialistas mayas que lo co-

${ }^{1}$ Este articulo deriva de mi tesis de doctorado, titulada Los dioses antropomorfos en el Códice Madrid.

Estudios de Cultura Maya. Vol. XXI, 2000

Instituto de Investigaciones Filológicas/

Centro de Estudios Mayas, UNAM

ISSN: 0185-2574 
nocían, los sacerdotes-intérpretes, los ah kines, chilames, lo manejaban cuidadosamente al leer los códices.

Aunque hay múltiples referencias históricas a los diferentes tipos de libros, cuyo contenido era muy variado, sólo se han conservado tres códices mayas adivinatorios: el de Dresde, el Madrid y el París. Mediante la observación de sus páginas, se pueden reconocer diversos asuntos, tanto por la presencia destacada de ciertos personajes, como por las actividades que parecen realizar -que en ocasiones son identificables, y que hoy llamamos secciones-. A su vez, cada una de estas secciones está organizada en varias unidades de contenido denominadas almanaques, ${ }^{2}$ término que en el siglo pasado los estudiosos de los códices aplicaron a aquellos pasajes que abarcan un ciclo completo de 260 días, y que contienen, además de las fechas, glifos e imágenes de los dioses. En otras palabras, los almanaques en los códices mayas son pequeñas secciones que constituyen una unidad temática y adivinatoria. Pero ¿cómo los leía el sacerdote?, ¿qué papel tenía cada uno de estos elementos en la adivinación?

Tomemos como muestra el Códice Madrid. Al ser el manuscrito maya más largo que conocemos, contiene el mayor número de ejemplos de textos adivinatorios. Quienes lo escribieron y quienes lo consultaron compartían una serie de creencias que están implícitas en la disposición peculiar de las fechas calendáricas, las imágenes de los dioses y los glifos. Estos tres elementos forman una unidad significativa, cuya separación por algunos estudiosos modernos no ha sido más que un recurso metodológico, encaminado a la comprensión de un texto sagrado, que para los mayas fue una expresión concreta de la voluntad divina.

\section{Los chilames: sacerdotes intérpretes}

Los especialistas yucatecos que realizaban los textos se denominaban $a b t s^{\prime} i b^{3}$ y $a b w o b,{ }^{4}$ es decir, escribas y pintores. Según Landa, éstos pertenecían al sector de los sacerdotes y de los nobles y, al parecer, existía entre ellos cierta libertad de vocación, pues afirma que les "enseñaban a los hijos de los otros sacerdotes y a los hijos segundos de los señores que les llevaban para esto [para aprender a escribir libros] desde niños, si veían que se inclinaban a este oficio". 5

Landa añade que en Yucatán el conocimiento calendárico, astronómico, ritual, médico y astrológico estaba en manos de los sacerdotes, que eran ellos quienes sabían leer y escribir, y quienes transmitían estos conocimientos únicamente a los hijos de sacerdotes y nobles. ${ }^{6}$

Sin embargo, parece que no todos los sacerdotes sabían escribir y leer; aunque es necesario realizar un estudio acerca de las diferentes fun-

\footnotetext{
${ }^{2}$ Voz de origen árabe (al-manaj) que deriva del latín manácbus, que significa 'círculos de los meses', y que fue empleada en Europa por Roger Bacon para designar las tablas que indicaban los movimientos visibles de los astros. En sus orígenes era un regalo de los astrólogos para sus principales en Año Nuevo y estaban dispuestos en forma de calendario con las divisiones del año en estaciones, meses y dias. También incluían predicciones, cuentos y anécdotas (Diccionario enciclopédico Espasa, t. 2, p. 530).

${ }^{3}$ Diccionario maya Cordemex, p. 882.

4 Ibidem, p. 924.

5 Landa, Relación de las cosas de Yucatân, p. 15. Información semejante encontramos en otros autores: Lizana apunta que los "hijos de los Sacerdotes de sus Dioses, que son los que sólo sabían leer y adivinar", Historia de Yucatán, p. 53; Ciudad Real, por su parte, dice que "Estas letras y caracteres no las entendian sino los sacerdotes de los ídolos y algún indio principal" (Tratado curioso y docto de las grandezas de la Nueva España, t. II, p. 319).
}

${ }^{6}$ Landa, Relación. 
ciones de los especialistas religiosos, parece que quienes se encargaban de dar a conocer el significado de los libros eran los chilames. Landa dice que "Chilam es el que tiene a su cargo dar las respuestas del demonio", 7 por lo que podemos pensar que era quien leía en los libros adivinatorios el lenguaje sagrado de las deidades. En el Diccionario de Motul a la voz $a b$ chila'n se atribuye el sentido de intérprete o naguatato. ${ }^{8}$ Mercedes de la Garza señala que entre los antiguos chamanes yucatecos están los chilames, hombres prodigiosos que profetizaban durante los trances extáticos.?

En todo el mundo, la profesión chamánica se transmite frecuentemente de manera hereditaria y en ocasiones se presenta como una "elección" divina, Los chamanes siempre reciben "una doble instrucción: primero, de orden extático (sue$\tilde{n} o s$, trances, etc.) y, segundo, de orden tradicional (técnicas chamánicas, nombres y funciones de los espíritus, mitología y genealogía del clan, lenguaje secreto, etcétera). ${ }^{10}$

En mi opinión, los chilames cumplen estas condiciones. Era una profesión hereditaria, en la que recibían una instrucción por parte de los otros sacerdotes y seguramente sufrian un proceso de iniciación. ${ }^{11}$ Después de éste, quizá durante un trance extático, estaban en posibilidad de comprender el lenguaje sagrado de los libros.

Aunque no existe ninguna descripción completa de cómo era la elección y el aprendizaje de un chilam, hay un pasaje en El libro de los $l i$ bros de Chilam Balam que parece narrar parte de ese proceso. Se trata de una profecía en la que se describe una ceremonia, durante la cual un grupo de sacerdotes ( $a b \mathrm{kin}$ ) asiste a la casa de otro que tenía el cargo de ab nacom, sacrificador, y que era a la vez chilam, es decir intérprete. Ahí, al empezar a oír "la palabra", todos se acostaron boca abajo. Posteriormente, el chilam saca un códice y lo coloca sobre un altar, donde oraban y lo consultaban durante tres días los ah kines.

Ésta es la memoria de cómo vino Hunab Ku, Deidad-Única, Oxlahun Tiku, Trece-Deidad, deidad inmensa (deidad de 800 veces) a decir su palabra a los Ah Kines, Sacerdotes-del-Culto-Solar, profetas <sic $\rangle$, Chilames Balames, Brujos-Intérpretes, al Ah Xupan Nahuat, El-Nahua-del-Estandarte-de-Turquesa, al Ah Kin, Sacerdote-del-Culto-Solar, Ah Napuctun, SeñorPiedra-Fina-de-Línea-Materna-llamado-Puc; al Ah Kin, Sacerdote-del-Culto-Solar, Ah Kauil Ch'el, El-Santo-Pájaro-Ch'el. Se reunieron en la casa del Ah Nacom Balam, el sacrificador-que-sacacorazones-brujo, que era Chilam, intérprete; entonces aconteció el hablar en la casa del Chilam, intérprete; les fueron dichas palabras de aviso y consejo, les fue revelada la medida de las palabras. Pero no entendieron estas palabras que les fueron dichas.

Comenzó a ser pronunciada la palabra cuando estaban reunidos los Ah Kines, Sacerdotesdel-Culto-Solar, en la casa del Chilam, intérprete. Les fue dicha la palabra a ellos, pero no sabían quién la decía que Hunab Ku, DeidadÚnica, Ahau Caan, Señor-del-Cielo, eso decían. Se postraron sobre la tierra cuando comenzaron a oír la palabra; se echaron de bruces. [Sigue una larga profecía sobre el katún de la Flor de Mayo, que finaliza diciendo:]

7 Ibid, p. 20.

${ }^{8}$ Diccionario maya Cordemex, p. 99. Cabe destacar que la voz nauatato posiblemente provenga del náhuatl y se refiera al nabualli, es decir al chamán. Véase De la Garza, Sueño y alucinación en el mundo nábuatl y maya, pp. 31-41.

9 De la Garza, Sueño..., p. 145.

${ }^{10}$ Eliade, El chamanismo, p. 29.

${ }^{11}$ Aunque no se ha encontrado ninguna referencia directa al proceso de iniciación de los chilames, hay una serie de evidencias tanto a través de las obras plásticas del mundo clásico como de la etnología contemporánea que nos permite afirmar su existencia. Véase De la Garza, Sueño..., pp. 148-149 y 171-212.

Estudios de Cultura Maya. Vol. XXI, 2000

Instituto de Investigaciones Filológicas/

Centro de Estudios Mayas, UNAM

ISSN: 0185-2574 
Muy dolorosamente terminará la humanidad de la Flor de Mayo según dicen las pinturas de las superficies de los muros, entonces diréis que también son santas y creeréis en su santidad. Aquel que sea sabio entre nosotros será el que comprenda esto [...] Dijo y sacó el libro de sus Siete-generaciones, para que lo leyesen los Ah Kines, Sacerdotes-del-Culto-Solar, durante tres días, pasándose mutuamente los Ah Kines, Sacerdotes-del-Culto-Solar. Primeramente el Yaaxche libro, libro-de-la-ceiba, le fue dado a $\mathrm{Ah}$ Xupan Nahuat, El-Nahua-del-Estandarte-de-Turquesa, a Ah Kin Ch'el, Sacerdote-del-Culto-Solar-Pájaro Ch'el, a Ah Napuctun, El-Piedra-Finade-Línea-Materna-llamada Hau. Estaba puesto el libro de las siete generaciones en el gran altar, el altar donde oraban Ah Kin Pech, Sacerdotedel-Culto-Solar-Garrapata, y Ah Kauil Ch'el, ElSanto-Pájaro-Ch'el, cuando oraban en el gran altar, en la gran mesa... ${ }^{12}$

Esta ceremonia tal vez podría corresponder a un proceso de iniciación de un grupo de ah kines, a quienes en un primer momento "les fueron dichas palabras de aviso y consejo, les fue revelada la medida de las palabras. Pero no entendieron estas palabras que les fueron dichas". ${ }^{13}$ Posteriormente comenzaron a oír "la palabra" y entonces se tendieron en el suelo boca abajo, para escuchar al Chilam Balam; cuando éste termina, ya son capaces de comprender el contenido de un libro que leen durante tres días.

Es posible que el texto aluda a un trance extático con las expresiones "se postraron sobre la tierra, se echaron de bruces". La tierra es, al decir de Eliade, la Tellus Mater, pues ella da y quita la vida. ${ }^{14}$ Este contacto con ella pudiera equipararse con un enterramiento simbólico, mediante el cual se representaron los dos momentos más importantes con los que se relaciona el proceso de iniciación: la muerte y el renacimiento. Según el texto, los sacerdotes leyeron el libro durante tres días, libro que estaba sobre un altar, símbolo del universo, y centro de comunicación con los dioses. Es entonces cuando el chilam dice "Eternamente se oirá mi voz, la del Chilam Balam, Brujo-Intérprete, explicando la palabra de Hahal Ku, Verdadera-Deidad". ${ }^{15}$

No se sabe a ciencia cierta cómo se consultaban los códices; sin embargo, la información etnográfica es una vía que permite acercarse a la manera en que el antiguo sacerdote-intérprete realizaba su labor, pues en algunos grupos contemporáneos aún sigue vigente el calendario sagrado de 260 días y es usado con fines adivinatorios por especialistas religiosos.

\section{El calendario de 260 dias}

En este antiguo calendario los 20 nombres de los días (que cambian de una lengua a otra y de una región a otra, aunque el orden y el significado son los mismos), se combinaban con 13 numerales de la misma manera en toda $\mathrm{Me}$ soamérica. El orden que presenta, seriado e ininterrumpido, marcó y sigue marcando los ritmos de los habitantes de Mesoamérica por lo menos desde hace dos milenios. ${ }^{16}$

Esquemáticamente se puede representar por veintenas, como se hace en el cuadro 1.

Los nombres más conocidos de estos días están en maya yucateco y corresponden a una serie de glifos que se reconocen y diferencian de

\footnotetext{
${ }^{12}$ El libro de los libros de Chilam Balam, pp. 94-98.

${ }^{13}$ Ibidem; subrayado nuestro.

${ }^{14}$ Chevalier, Diccionario de los símbolos, p. 992.

15 El libro de los libros de Cbilam Balam, p. 99.

${ }^{16}$ Véase Ayala, El año de 260 dias en Mesoamérica... Estudios de Cultura Maya. Vol. XXI, 2000 


\section{Cuadro 1}

Calendario de 260 dias. Un ciclo completo ${ }^{\text {a }}$

\begin{tabular}{llllllllllllll}
\hline & \multicolumn{1}{c}{ Veintenas } \\
\hline Días & $1 \mathrm{a}$. & $2 \mathrm{a}$. & $3 \mathrm{a}$. & $4 \mathrm{a}$. & $5 \mathrm{a}$. & $6 \mathrm{a}$. & $7 \mathrm{a}$. & $8 \mathrm{a}$. & $9 \mathrm{a}$. & $10 \mathrm{a}$. & $11 \mathrm{a}$. & $12 \mathrm{a}$. & $13 \mathrm{a}$. \\
\hline Imix & 1 & 8 & 2 & 9 & 3 & 10 & 4 & 11 & 5 & 12 & 6 & 13 & 7 \\
Ik & 2 & 9 & 3 & 10 & 4 & 11 & 5 & 12 & 6 & 13 & 7 & 1 & 8 \\
Akbal & 3 & 10 & 4 & 11 & 5 & 12 & 6 & 13 & 7 & 1 & 8 & 2 & 9 \\
Kan & 4 & 11 & 5 & 12 & 6 & 13 & 7 & 1 & 8 & 2 & 9 & 3 & 10 \\
Chicchan & 5 & 12 & 6 & 13 & 7 & 1 & 8 & 2 & 9 & 3 & 10 & 4 & 11 \\
Cimi & 6 & 13 & 7 & 1 & 8 & 2 & 9 & 3 & 10 & 4 & 11 & 5 & 12 \\
Manik & 7 & 1 & 8 & 2 & 9 & 3 & 10 & 4 & 11 & 5 & 12 & 6 & 13 \\
Lamat & 8 & 2 & 9 & 3 & 10 & 4 & 11 & 5 & 12 & 6 & 13 & 7 & 1 \\
Muluc & 9 & 3 & 10 & 4 & 11 & 5 & 12 & 6 & 13 & 7 & 1 & 8 & 2 \\
Oc & 10 & 4 & 11 & 5 & 12 & 6 & 13 & 7 & 1 & 8 & 2 & 9 & 3 \\
Cbuen & 11 & 5 & 12 & 6 & 13 & 7 & 1 & 8 & 2 & 9 & 3 & 10 & 4 \\
Eb & 12 & 6 & 13 & 7 & 1 & 8 & 2 & 9 & 3 & 10 & 4 & 11 & 5 \\
Ben & 13 & 7 & 1 & 8 & 2 & 9 & 3 & 10 & 4 & 11 & 5 & 12 & 6 \\
Ix & 1 & 8 & 2 & 9 & 3 & 10 & 4 & 11 & 5 & 12 & 6 & 13 & 7 \\
Men & 2 & 9 & 3 & 10 & 4 & 11 & 5 & 12 & 6 & 13 & 7 & 1 & 8 \\
Cib & 3 & 10 & 4 & 11 & 5 & 12 & 6 & 13 & 7 & 1 & 8 & 2 & 9 \\
Caban & 4 & 11 & 5 & 12 & 6 & 13 & 7 & 1 & 8 & 2 & 9 & 3 & 10 \\
Etz'nab & 5 & 12 & 6 & 13 & 7 & 1 & 8 & 2 & 9 & 3 & 10 & 4 & 11 \\
Cauac & 6 & 13 & 7 & 1 & 8 & 2 & 9 & 3 & 10 & 4 & 11 & 5 & 12 \\
Abau & 7 & 1 & 8 & 2 & 9 & 3 & 10 & 4 & 11 & 5 & 12 & 6 & 13 \\
\hline
\end{tabular}

- Ayala, El año de 260 días en Mesoamérica.

los demás jeroglíficos mayas por estar encerrados en una especie de marco o cartucho:

imix, ik, akbal, kan, chicchan, cimi, manik, lamat, muluc, oc, cbuen, eb, ben, $i x$, men, $c i b$, caban, etz'nab, cauac y abau.

En los códices, los numerales que los acompañan están representados con el sistema de puntos $(\cdot)$ y barras $\Longleftrightarrow$, de tal manera que, por ejemplo, el número tres se escribía con $\ldots$, el ocho con ... y el trece con .... El numeral 20 se escribía en estos manuscritos con el signo de la Luna.

\section{¿Qué fechas contienen los almanaques de los códices? ${ }^{17}$}

Debido a que cada almanaque abarca un ciclo completo de 260 días, dice Thompson que los sacerdotes mayas idearon representarlos de manera abreviada y siguiendo pautas definidas que permiten una rápida y fácil identificación: ${ }^{18}$ se inician con una columna de glifos compuesta por una serie de los signos del calendario de 260 dias, que se colocaban a la izquierda. Sobre ésta hay un numeral en color rojo y a la derecha, generalmente a la altura del primer glifo, pero dispuestos horizontalmente y a lo largo de todo el

${ }^{17}$ Una parte de este apartado se publicó en la revista Arqueología Mexicana, vol. 22, como un recuadro complementario a mi artículo "Los códices mayas".

${ }_{18}$ Thompson, Un comentario..., p. 64. 
Figura 1. Glifos de los días

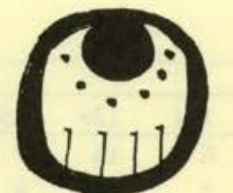

Imix

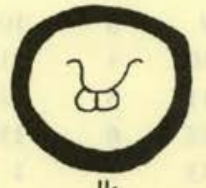

Ik

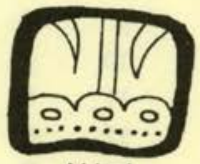

Akbal

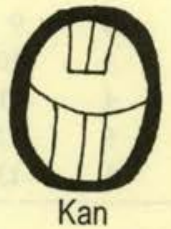

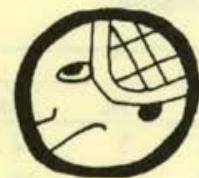

Chicchan

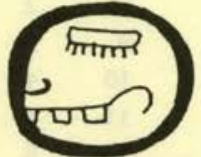

Cimi

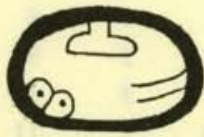

Manik

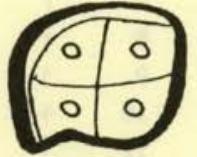

Lamat

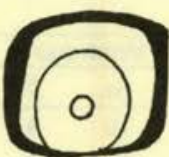

Muluc

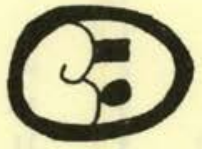

Oc

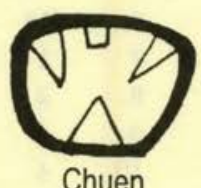

Chuen

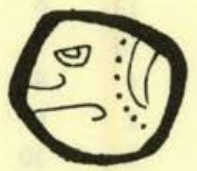

$\mathrm{Eb}$

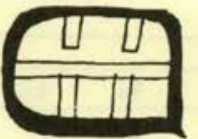

Ben

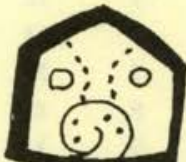

$\mathrm{Ix}$

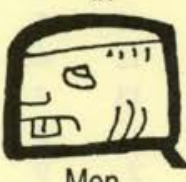

Men

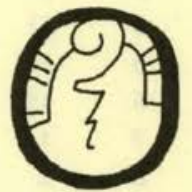

Cib

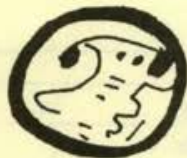

Caban

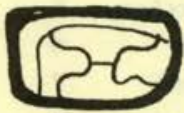

Etznab

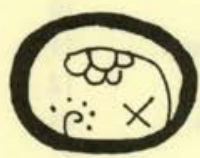

Cauac

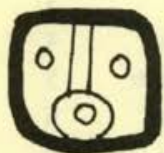

Ahau

Basado en Thompson, 1971. Dibujó Moisés Aguirre

almanaque, hay dos series de números: unos negros y otros rojos. Los números rojos son siempre el coeficiente del día, $y$ los negros indican el número de días que hay entre una fecha y otra. Si la columna de la izquierda consta de cinco glifos, entonces la suma de los números negros será de $52(260+5=52)$; si hay cuatro glifos, el total de los números negros equivaldrá a 65 $(260 \div 4=65) .{ }^{19} \mathrm{El}$ sacerdote entonces, teniendo como punto de partida la fecha inicial del almanaque que estaba escrita mediante un numeral rojo y el signo del día en negro, comenzaba a contar hacia adelante el número de días que le indicaba el numeral negro y así llegaba a la siguiente fecha que sólo estaba sugerida mediante el numeral rojo. El proceso se repetía hasta que concluía con ese primer renglón, al final del cual llegaba a la siguiente fecha anotada en la columna izquierda. Si seguía contando hacia adelante, después de recorrer todas las fechas escritas y sugeridas, llegaba finalmente al punto inicial, completando el ciclo.

Tomemos como ejemplo el almanaque de la página 26d del Códice Madrid. El almanaque comienza con dos columnas de cinco glifos cada una que tienen en la parte superior el número 13 escrito en rojo. De arriba abajo, y de izquierda a derecha, están los días imix, manik, ben, cauac, chicchan, chuen, caban, akbal, muluc y ben. En tanto que hay 10 días escritos, y el calendario es de 260 , la suma total de los números negros debe ser de $26(260 \div 10=26)$. Efectivamente, están anotados los numerales 9, 3, 10, 2 y 2 , que dan un total de 26. Además se encuentran los nú-

\footnotetext{
19 Ibidem BPBs 64-65itura Maya. Vol. XXI, 2000 


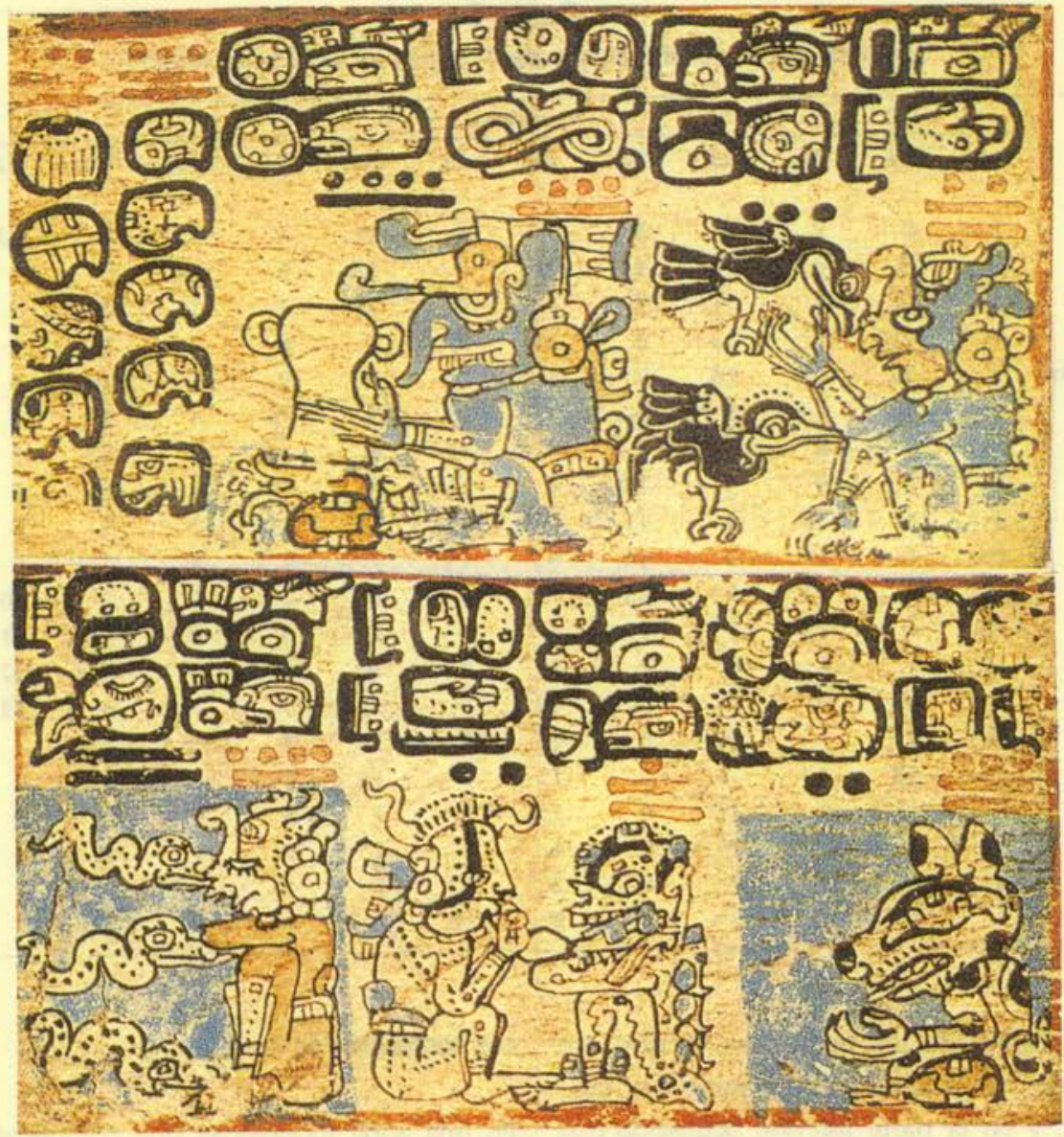

Figura 2. Códice Madrid, pp. 26d-27c

meros rojos $9,12,9,11$ y 13 , que señalan las fechas del calendario a las que se llega sumando los números negros.

Con caracteres latinos y números arábigos, pero conservando la misma disposición que en el Códice Madrid, este almanaque se escribiría así:
Cada par de números negros y rojos ocupaba el espacio equivalente a lo que se podría llamar una columna, y que Thompson llamó, de acuerdo con los diccionarios coloniales, $t^{\prime} \mathrm{ol} .{ }^{20} \mathrm{El}$ espacio que cada t'ol ocupa lo determinó muchas veces el escriba mediante una finísima lí-

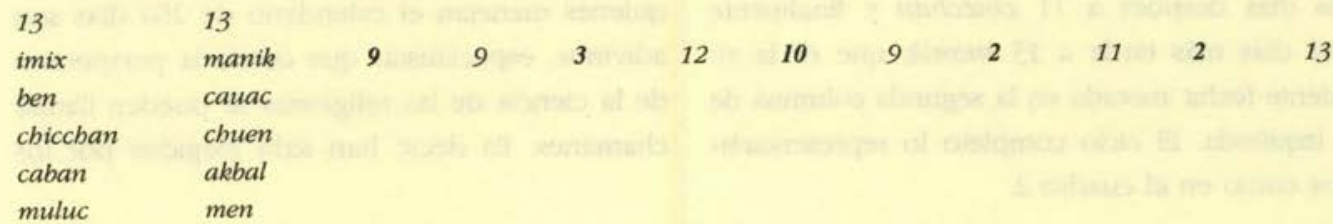

${ }^{20} \mathrm{Ibid}$. p. 50.

Estudios de Cultura Maya. Vol. XXI, 2000

Instituto de Investigaciones Filológicas/

Centro de Estudios Mayas, UNAM 


\section{Cuadro 2}

Representación del almanaque de la página 26 del Códice Madrid

\begin{tabular}{|c|c|c|c|c|c|c|c|c|c|c|c|c|c|}
\hline \multirow[t]{2}{*}{ Días } & \multicolumn{13}{|c|}{ Veintenas } \\
\hline & $1 a$. & $2 a$. & $3 a$. & $4 a$. & $5 a$. & $6 a$ & $7 a$ & $8 a$. & $9 \mathrm{a}$. & $10 \mathrm{a}$. & $11 \mathrm{a}$. & $12 \mathrm{a}$. & $13 \mathrm{a}$. \\
\hline $\operatorname{Im} i x$ & 1 & 8 & 2 & 9 & 3 & 10 & 4 & 11 & 5 & 12 & 6 & 13 & 7 \\
\hline$I k$ & 2 & 9 & 3 & 10 & 4 & 11 & 5 & 12 & 6 & 13 & 7 & 1 & 8 \\
\hline Akbal & 3 & 10 & 4 & 11 & 5 & 12 & 6 & 13 & 7 & 1 & 8 & 2 & 9 \\
\hline Kan & 4 & 11 & 5 & 12 & 6 & 13 & 7 & 1 & 8 & 2 & 9 & 3 & 10 \\
\hline Cbicchan & 5 & 12 & 6 & 13 & 7 & 1 & 8 & 2 & 9 & 3 & 10 & 4 & 11 \\
\hline Cimi & 6 & 13 & 7 & 1 & 8 & 2 & 9 & 3 & 10 & 4 & 11 & 5 & 12 \\
\hline Manik & 7 & 1 & 8 & 2 & 9 & 3 & 10 & 4 & 11 & 5 & 12 & 6 & 13 \\
\hline Lamat & 8 & 2 & 9 & 3 & 10 & 4 & 11 & 5 & 12 & 6 & 13 & 7 & 1 \\
\hline Muloc & 9 & 3 & 10 & 4 & 11 & 5 & 12 & 6 & 13 & 7 & 1 & 8 & 2 \\
\hline$O c$ & 10 & 4 & 11 & 5 & 12 & 6 & 13 & 7 & 1 & 8 & 2 & 9 & 3 \\
\hline Chuen & 11 & 5 & 12 & 6 & 13 & 7 & 1 & 8 & 2 & 9 & 3 & 10 & 4 \\
\hline$E b$ & 12 & 6 & 13 & 7 & 1 & 8 & 2 & 9 & 3 & 10 & 4 & 11 & 5 \\
\hline Ben & 13 & 7 & 1 & 8 & 2 & 9 & 3 & 10 & 4 & 11 & 5 & 12 & 6 \\
\hline$I x$ & 1 & 8 & 2 & 9 & 3 & 10 & 4 & 11 & 5 & 12 & 6 & 13 & 7 \\
\hline Men & 2 & 9 & 3 & 10 & 4 & 11 & 5 & 12 & 6 & 13 & 7 & 1 & 8 \\
\hline$C i b$ & 3 & 10 & 4 & 11 & 5 & 12 & 6 & 13 & 7 & 1 & 8 & 2 & 9 \\
\hline Caban & 4 & 11 & 5 & 12 & 6 & 13 & 7 & 1 & 8 & 2 & 9 & 3 & 10 \\
\hline Etz'nab & 5 & 12 & 6 & 13 & 7 & 1 & 8 & 2 & 9 & 3 & 10 & 4 & 11 \\
\hline Cauac & 6 & 13 & 7 & 1 & 8 & 2 & 9 & 3 & 10 & 4 & 11 & 5 & 12 \\
\hline Abau & 7 & 1 & 8 & 2 & 9 & 3 & 10 & 4 & 11 & 5 & 12 & 6 & 13 \\
\hline
\end{tabular}

nea roja; arriba de los numerales escribió un breve texto compuesto generalmente por cuatro glifos, y en la parte inferior, ocupando casi tres cuartas partes del espacio, una figura muchas veces antropomorfa.

Si señaláramos las fechas de este almanaque dentro de un ciclo completo, comenzaríamos en la decimosegunda veintena, con 13 imix, y continuariamos contando nueve días hacia abajo, hasta llegar a 9 oc; tres días más tarde, llegaríamos a 12 ben, dos días después a 9 akbal, dos días después a 11 chicchan y finalmente diez días más tarde a 13 manik, que es la siguiente fecha anotada en la segunda columna de la izquierda. El ciclo completo lo representaríamos como en el cuadro 2.

\section{Los contadores de los dias}

En una zona montañosa que comprende la región noreste de Chiapas y continúa en Guatemala están distribuidos los chujes, ixiles, quichés, cakchiqueles y pokomchís quienes aún emplean el calendario de 260 días. De ellos no sólo se tienen referencias de los nombres de los días de este calendario, ${ }^{21}$ sino también de las maneras en que éste se emplea para adivinar.

En términos generales, se puede señalar que quienes manejan el calendario de 260 días son adivinos, especialistas que desde la perspectiva de la ciencia de las religiones se pueden llamar chamanes. Es decir, han sido elegidos por los 
dioses, llamados en sueños e iniciados. Su labor es muy estimada en su comunidad.

Hay una gran semejanza en la manera en que estos sacerdotes emplean el calendario sagrado para conocer los designios de los dioses, y los registros de almanaques que han quedado asentados en los códices. Por esto realizaré una comparación de algunos elementos presentes entre ixiles y quichés con los contenidos en el Códice Madrid.

A mi modo de ver, los dos trabajos me brindan la información más clara para comprender la adivinación maya mediante el calendario de 260 días son los de Tedlock y los Colby. El primero de ellos estudia la adivinación quiché en general: Quiche Maya Divination: a Theory of Practice, y en él aclara muchos aspectos en cuanto al significado religioso de los días, y la manera en que se deben interpretar. El segundo, titulado El contador de los días, reúne la información dada por Shas Ko'w, adivino ixil, quien manejaba el antiguo calendario sagrado para contar los días, empleando semillas de mic. Este personaje es un especialista religioso que se conoce como "contador de los días" o 'aaq'ii. 22

Entre los ixiles el aprendizaje de este calendario se presenta como una revelación en sueños; no existe una transmisión directa de un maestro al futuro sacerdote, sino que, según sus creencias, los dioses-días son quienes eligen al contador de los días, y se les manifiestan al sonar. Según refirió Shas Ko’w, "Nadie me instruyó acerca de los Días, simplemente soñé con ellos, y luego fui a preguntar al rezador qué significaban los sueños". ${ }^{23}$ Así, él conoció el calendario, y lo que podríamos llamar el aprendizaje formal se lo dio el rezador, quien le transmitió el sentido de sus sueños. Después de un largo proceso, reunió su envoltorio y empezó a adivinar. ${ }^{24}$

El conocimiento que recibió en sueños sobre el calendario, los Colby lo resumen así:

Cada día del calendario está representado por una deidad con atributos especiales, que se emplean para hacer una lectura o diagnóstico adivinatorio. Los patronos de los días revelan la causa subyacente de una enfermedad o un infortunio al contador de los días, el cual pasa esta información al enfermo. ${ }^{25}$

Shas les dio valiosa información sobre las características y funciones de los días que sin duda proviene de tiempos prehispánicos, y que se puede enumerar a grandes rasgos. En primer lugar hay que destacar que dada día es considerado una deidad, la cual se invoca con términos rituales particulares; cada dios-día rige desde el alba hasta después de media noche, cada día tiene un oficio correspondiente a los puestos del gobierno civil, algunos días son considerados buenos, otros malos y más son casi neutros. ${ }^{26}$ "El significado literal de los nombres de los días no siempre es representación directa de los atributos", y al parecer todos los contadores de los días están de acuerdo en los atributos de cada día. ${ }^{27}$

\footnotetext{
22 Este término recuerda el que se empleaba en Yucatán en tiempos prehispánicos, ab kin, por lo que tal vez estemos ante una palabra cognada.

${ }^{23}$ Colby y Colby, El contador de los días, p. 77. Aquí vale la pena destacar que sus sueños tienen elementos comunes a los de las iniciaciones chamánicas de otras latitudes: Shas Ko'w soñó que ascendía al cielo mediante una cuerda y que volaba. Estos símbolos arquetípicos bien merecen un estudio aparte.

${ }^{24}$ Un estudio sobre los sueños iniciáticos de los futuros contadores de los días aclararía este complejo asunto del aprendizaje no formal.

${ }^{25}$ Colby y Colby, El contador de los días, pp. 238-239.

${ }^{26}$ Ibid., pp. 238-239.

${ }^{27}$ Ibid., pp. 239-240.
} 


\section{Cuadro 3}

Nombres ixiles de los 20 dias del calendario de 260 dias

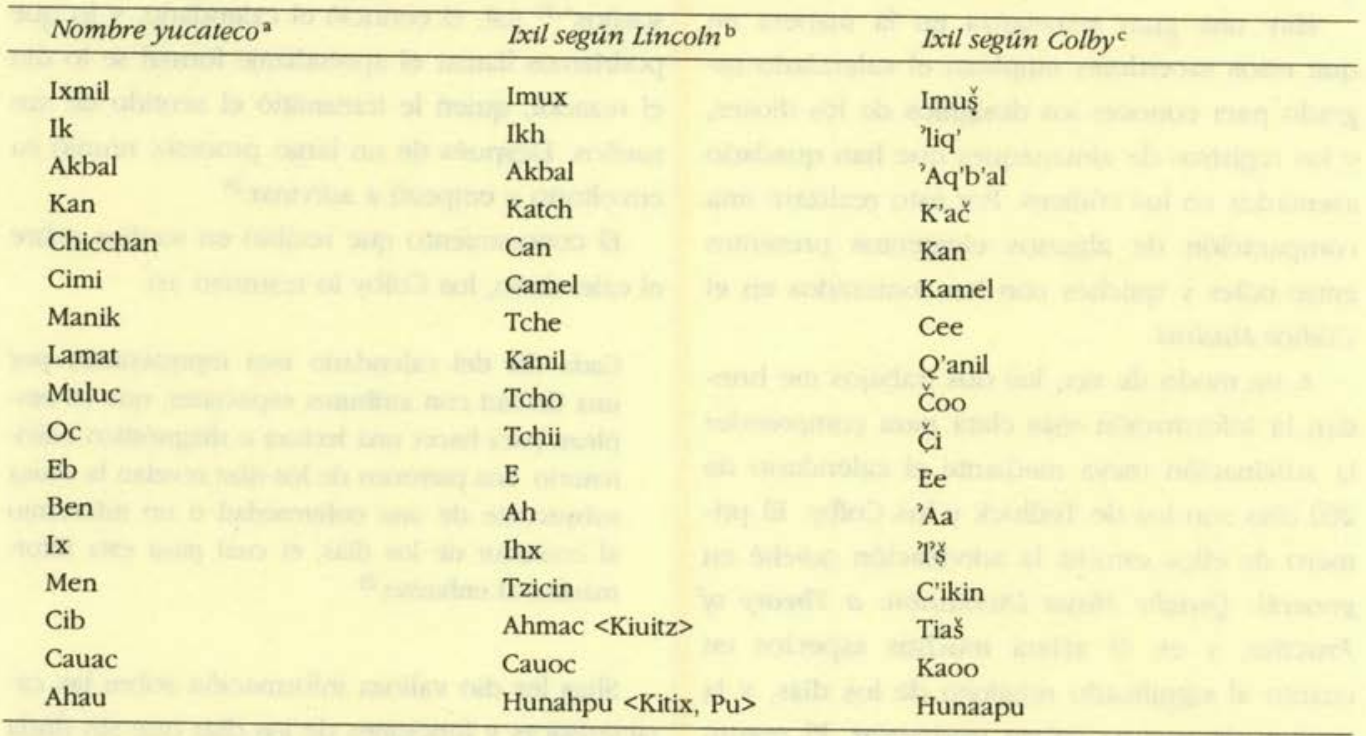

'Según Thompson, en Maya Hieroglypbic Writing, p. 68.

${ }^{\mathrm{b}}$ Lincoln, The Maya Calendar of the Ixil of Guatemala, citado en Thompson, Maya Hieroglypbic Writing, p. 68.

'Colby, El contador de los dias, p. 243.

Los 20 días ixiles se listan en el cuadro 3.

Los números que acompañan a cada día pueden tener un sentido positivo, negativo o neutro; el 9 y el 13 tienen un sentido negativo y, en algunos casos, "los números de días dan un significado cuantificado", y al parecer no representan deidades distintas. Hay ciertas fechas que son especialmente significativas, algunas en relación con los sueños, otras con la suerte y otras más para el ritual. ${ }^{28}$

Entre los quichés, Barbara Tedlock aprendió el calendario y sus atributos, e inclusive fue iniciada en agosto de 1976, por lo que pudo realizar adivinaciones para clientes quichés. ${ }^{29}$

Tedlock aborda cuatro aspectos del calendario de 260 días que se han discutido en la biblio- grafia tanto epigráfica como etnográfica; el primero es el que se refiere a la duración de este ciclo que, según afirman los quichés, equivale al tiempo de la gestación humana; ${ }^{30}$ en cuanto a la existencia de un día que inicie este calendario, más bien encontró que puede iniciarse con el portador del año, con el día más reciente que lleve el número 1 o con cualquier otro para iniciar la cuenta. ${ }^{31} \mathrm{El}$ tercer asunto es el de la caracterización de cada dia: ¿qué días son buenos y qué días son malos? Teodlock prefiere no imponerles un valor absoluto, pues éste depende de diversos factores, como veremos más adelante; y el último asunto que trata es el referente a la traducción de los días, del que comenta: "Pero cuando uno ha aprendido el calendario, uno

\footnotetext{
${ }^{28}$ Ibid., p. 240.

29 Tedlock, Quiché Maya Divination, p. 9.

${ }^{30}$ Ibid., p. 114.

${ }^{31}$ Ibid., p. 120.

Estudios de Cultura Maya. Vol. XXI, 2000

Instituto de Investigaciones Filológicas/

Centro de Estudios Mayas, UNAM 


\section{Cuadro 4}

Nombres quichés de los 20 días del calendario de 260 días

\begin{tabular}{lll}
\hline Nombre $_{\text {yucateco }}{ }^{\mathrm{a}}$ & Quiché segün Goubaud & Quiché según Tedlock $^{\mathrm{b}}$ \\
\hline Imix & Imox & Imöx \\
Ik & Ikh & Ik' \\
Akbal & Akhabal & Ak'bal \\
Kan & Kat & C'at \\
Chicchan & Can & Can \\
Cimi & Came & Came \\
Manik & Cieh & Quej \\
Lamat & Khanil & K'anil \\
Muluc & Toh & Toj \\
Oc & Tz'i & Tz'i \\
Chuen & Batz & Batz' \\
Eb & Eeh & E \\
Ben & Ah & Aj \\
Ix & Ix & Ix \\
Men & Tzicin & Tz'iquin \\
Cib & Ahmac & Ajmac \\
Caban & Noh & No'j \\
Etznab & Tihax & Tijax \\
Cauac & Cauac & Cawuk \\
Ahau & Hunahpu & Junajpu \\
\hline
\end{tabular}

${ }^{a}$ Según Thompson, Maya Hieroglyphic Writing, p. 68.

${ }^{b}$ Lincoln, The Maya Calendar of the Ixil of Guatemala, citado en Thompson, Maya Hieroglyphic Writing, p. 68.

'Colby y Colby, El contador de los días, p. 243.

acude a una serie de recursos mnemotécnicos que conforma el significado social de esos días y no las etimologías de esos nombres". ${ }^{32}$

Los 20 días quichés se registran en el cuadro 4 .

Señala además que los numerales afectan el sentido de un día dado, pero que éstos no conforman una unidad con el día. Más bien los números bajos son considerados ligeros o suaves, pues indican algo joven o nuevo, mientras que los números altos son poderosos y aun violentos, pues indican cosas viejas, maduras o más serias. $^{33}$

El "rostro de los días" es complejo, y es- tá compuesto por tres significados principales: una serie de términos que ella denominó "mnemotécnicos", los rituales y los adivinatorios. Los términos mnemotécnicos, fundamentales en el aprendizaje oral, están intimamente relacionados con la vida ritual. Además, toma en cuenta el numeral que le imprime valencias específicas al día, a la vez que valora las influencias del nawal, que caracteriza también a los niños nacidos en ese día. Durante la adivinación el sacerdote debe seleccionar entre los distintos significados y las asociaciones rituales "una respuesta coherente pero inspirada a la pregunta del cliente". ${ }^{34}$

\footnotetext{
32 Ibid., p. 124. Traducción mía.

${ }^{33}$ Ibid., p. 125.

${ }^{34}$ Ibid., p. 127. Traducción mía.
} 


\section{La adivinación}

Esta práctica se ejerce principalmente en la vivienda del sacerdote, aunque en ocasiones éste puede ir a casa de algún cliente. Para realizarla, Shas Ko'w emplea su envoltorio (meesa), es decir el pedazo de tela que contiene un puñado de cristales de cuarzo y cierto número de semillas del árbol de coral. ${ }^{35}$ En otras partes del libro los autores destacan que las semillas son de mic.

Los sacerdotes quichés emplean también un envoltorio que contiene semillas y cristales de cuarzo; lo extienden sobre una mesa, colocan las plantas de los pies firmemente sobre el piso, rezan, y entonces el cliente puede iniciar el proceso adivinatorio, realizando su pregunta. El sacerdote desata el bulto, revuelve las semillas y los cristales, generalmente con la mano derecha y en sentido contrario al de las manecillas del reloj. Entonces selecciona 10 cristales y los dispone de tal manera que "representa la estructura de autoridad tradicional del pueblo" ${ }^{36}$

A continuación el adivino toma un puño de semillas y cristales y los coloca en línea en grupos de cuatro, de izquierda a derecha, sobre la mesa, puede formar cinco y ocho filas, y el número de semillas que conforman la última fila puede variar de las anteriores, y el último grupo debe estar formado por una, dos o cuatro semillas y/o cristales, pero nunca por tres. Una vez que están dispuestas así, el sacerdote denomina al primer conjunto de semillas por el nombre del día en que está realizando la adivinación, e inicia la cuenta de los días de izquierda a derecha, siguiendo el orden seriado e ininterrumpido del calendario de 260 dias. Una vez que ha recorrido todos los grupos de semillas y cristales, denominándolos conforme al orden del calendario, sigue con la cuenta iniciando nuevamente en la parte superior izquierda, y recorriendo otra vez las semillas.

El contador de los días ixil, procede de manera semejante: toma un puñado de semillas y las coloca por pares en líneas, comenzando de izquierda a derecha, hasta formar un conjunto de varias columnas; comienza la lectura de izquierda a derecha, a partir del día de la lectura (o bien del día en que se había manifestado una enfermedad), y los pares de semillas que conforman la columna extrema de la derecha son los "días parlantes", es decir aquellos que le permiten al sacerdote conocer la voluntad divina. Sin embargo, hay otras parejas de semillas que pueden encontrarse en cualquier parte $\mathrm{y}, \mathrm{si}$ eran especialmente sobresalientes, también podian hablar. ${ }^{37}$

Veamos el ejemplo que presentan los Colby. Si comparamos la disposición que los sacerdotes quichés e ixiles les dan a las semillas, al asignarles los diferentes dias del calendario sagrado, con los almanaques representados en los códices, se ve claramente que se está empleando el mismo sistema de adivinación; en los códices hay glifos para el nombre de cada día y

Cuadro 5

\begin{tabular}{|c|c|c|c|c|c|c|c|c|c|}
\hline 10 & $\mathrm{Bac}$ & 1 & 1Ee & 12 & 'Aa & 13 & 'Is & $1 C^{\prime}$ ikin & 2 'Aama \\
\hline 3 & No'o & 4 & Tiaš & 5 & Каоо & 6 & Hunaapu & 7 Imuš & 8 'liq' \\
\hline 9 & 'Aq'b'al & 10 & k'ač & 1 & lkan & 12 & Kamel & $13 \mathrm{Cee}$ & 1 Q'anil \\
\hline 2 & $\mathrm{CoO}$ & 3 & Ç̌i & 4 & B'aac & 5 & $\mathrm{Ee}$ & $6^{\prime} A a^{*}$ & \\
\hline
\end{tabular}

- Colby y Colby, El contador de los días, p. 243. Los días parlantes están en negritas.

35 Ibid., p. 242.

36 Tedlock, Quiche Mayan Divination, p. 218.

${ }^{37}$ Colby y Colby El contador de los días, E $^{242 .}$ Instituto de Investigaciones Filológicas/ 
Cuadro 6

Calendario de 260 días. Un ciclo completo

\begin{tabular}{|c|c|c|c|c|c|c|c|c|c|c|c|c|c|}
\hline \multirow[t]{2}{*}{ Día } & \multicolumn{13}{|c|}{ Veintena } \\
\hline & $1 a$. & $2 a$. & $3 a$. & $4 a$. & $5 a$. & $6 a$. & $7 a$. & $8 a$. & $9 a$. & $10 a$. & $11 a$. & $12 a$. & $13 a$. \\
\hline Imix & 1 & 8 & 2 & 9 & 3 & 10 & 4 & 11 & 5 & 12 & 6 & 13 & 7 \\
\hline$I k$ & 2 & 9 & 3 & 10 & 4 & 11 & 5 & 12 & 6 & 13 & 7 & 1 & 8 \\
\hline Akbal & 3 & 10 & 4 & 11 & 5 & 12 & 6 & 13 & 7 & 1 & 8 & 2 & 9 \\
\hline Kan & 4 & 11 & 5 & 12 & 6 & 13 & 7 & 1 & 8 & 2 & 9 & 3 & 10 \\
\hline Chicchan & 5 & 12 & 6 & 13 & 7 & 1 & 8 & 2 & 9 & 3 & 10 & 4 & 11 \\
\hline Cimi & 6 & 13 & 7 & 1 & 8 & 2 & 9 & 3 & 10 & 4 & 11 & 5 & 12 \\
\hline Manik & 7 & 1 & 8 & 2 & 9 & 3 & 10 & 4 & 11 & 5 & 12 & 6 & 13 \\
\hline Lamat & 8 & 2 & 9 & 3 & 10 & 4 & 11 & 5 & 12 & 6 & 13 & 7 & 1 \\
\hline Muluc & 9 & 3 & 10 & 4 & 11 & 5 & 12 & 6 & 13 & 7 & 1 & 8 & 2 \\
\hline$O c$ & 10 & 4 & 11 & 5 & 12 & 6 & 13 & 7 & 1 & 8 & 2 & 9 & 3 \\
\hline Chuen & 11 & 5 & 12 & 6 & 13 & 7 & 1 & 8 & 2 & 9 & 3 & 10 & 4 \\
\hline$E b$ & 12 & 6 & 13 & 7 & 1 & 8 & 2 & 9 & 3 & 10 & 4 & 11 & 5 \\
\hline Ben & 13 & 7 & 1 & 8 & 2 & 9 & 3 & 10 & 4 & 11 & 5 & 12 & 6 \\
\hline$I x$ & 1 & 8 & 2 & 9 & 3 & 10 & 4 & 11 & 5 & 12 & 6 & 13 & 7 \\
\hline Men & 2 & 9 & 3 & 10 & 4 & 11 & 5 & 12 & 6 & 13 & 7 & 1 & 8 \\
\hline$C i b$ & 3 & 10 & 4 & 11 & 5 & 12 & 6 & 13 & 7 & 1 & 8 & 2 & 9 \\
\hline Caban & 4 & 11 & 5 & 12 & 6 & 13 & 7 & 1 & 8 & 2 & 9 & 3 & 10 \\
\hline Etznab & 5 & 12 & 6 & 13 & 7 & 1 & 8 & 2 & 9 & 3 & 10 & 4 & 11 \\
\hline Cauac & 6 & 13 & 7 & 1 & 8 & 2 & 9 & 3 & 10 & 4 & 11 & 5 & 12 \\
\hline Abau & 7 & 1 & 8 & 2 & 9 & 3 & 10 & 4 & 11 & 5 & 12 & 6 & $13^{a}$ \\
\hline
\end{tabular}

${ }^{a}$ Los días parlantes están en negritas y en cursivas el día inicial de la cuenta (el 10 en la 12a. columna).

números negros y rojos para el numeral, y el de los sacerdotes contemporáneos que emplean semillas y cristales. La disposición y la manera de contar son las mismas.

En el ejemplo de los Colby, el sacerdote inició la cuenta en un día 10 B'aac', que en términos yucatecos equivale a 10 Chuen. Cinco días más adelante, llega a 2 Aama, primer día parlante, que en yucateco equivale a $2 \mathrm{Cib} ; 12$ días después llega a 1 Q'anil, tercer día parlante, es decir a 1 Lamat y concluye con $6 \mathrm{Aa}$, es decir 6 Ben, que es el último día parlante.

Si nosotros colocamos esquemáticamente esta disposición de los días dentro de un ciclo completo de 260 días acomodado por veintenas y usando los nombres yucatecos, esta disposición resultaría como en el cuadro 6.

Si esta misma disposición la expresáramos de acuerdo con el sistema de almanaques de los có- dices mayas, la fecha inicial 10 Chuen se escribiría en el margen izquierdo, los cinco días siguientes se anotarían en tinta negra mediante una barra, y el día 2 Cib se indicaria mediante dos puntos rojos. Los siguientes seis dias nuevamente se anotarian con un punto y una barra en color negro y la fecha a la que se llegaría sería $8 \mathrm{lk}$, abreviada, pues solamente estaria escrito un numeral 8 en color rojo; seis días después, escrito mediante un numeral 6 en tinta negra, se llega a la siguiente fecha que es 1 Lamat, representado con un punto rojo, y finalmente se añaden cinco días que, sumados a la fecha anterior, equivalen a 6 Ben, que es el último día parlante.

La suma de los números negros, en este caso, da un total de 22 días, cifra muy cercana a la que se encuentra en los códices cuando los almanaques presentan 10 divisiones de 26 días cada una. A manera de ejemplo, podríamos añadir 


\section{Cuadro 7}

\begin{tabular}{|c|c|c|c|c|c|c|c|c|c|c|c|}
\hline 10 & Chuen $+5=$ & 2 & $C i b+6=$ & 8 & $l k+6=$ & 1 & Lamat $+5=$ & $\underline{6}$ & Ben $+4=$ & 10 & Caban \\
\hline 10 & Caban $+5=$ & 2 & $1 k+6=$ & 8 & lamat $+6=$ & 1 & $1 x+5=$ & 6 & Cauac $+4=$ & 10 & Akbal \\
\hline 10 & $\mathrm{Akbal}+5=$ & 2 & Lamat $+6=$ & 8 & $1 x+6=$ & 1 & Ahau $+5=$ & 6 & Chicchan $+4=$ & 10 & Muluc \\
\hline 10 & Muluc $+5=$ & 2 & $1 x+6=$ & 8 & Ahau $+6=$ & 1 & $\mathrm{Cimi}+5=$ & 6 & Chuen $+4=$ & 10 & Men \\
\hline 10 & Men $+5=$ & 2 & Ahau $+6=$ & 8 & $\mathrm{Cimi}+6=$ & 1 & $E b+5=$ & 6 & Cabán+4= & 10 & Imix \\
\hline 10 & $\operatorname{Imix}+5=$ & 2 & $\mathrm{Cimi}+6=$ & 8 & $\mathrm{~Eb}+6=$ & 1 & Etznab $+5=$ & 6 & Akbal $+4=$ & 10 & Manik \\
\hline 10 & Manik $+5=$ & 2 & $E b+6=$ & 8 & Etznab $+6=$ & 1 & $\mathrm{Kan}+5=$ & 6 & Muluc $+4=$ & 10 & Ben \\
\hline 10 & Ben $+5=$ & 2 & Etznab $+6=$ & 8 & $\mathrm{Kan}+6=$ & 1 & $O c+5=$ & 6 & Men $+4=$ & 10 & Cauac \\
\hline 10 & Cauac $+5=$ & 2 & $\mathrm{Kan}+6=$ & 8 & $O c+6=$ & 1 & $\mathrm{Cib}+5=$ & 6 & $\operatorname{Imix}+4=$ & 10 & Chicchan \\
\hline 10 & Chicchan $+5=$ & 20 & $c+6=$ & 8 & $\mathrm{Cib}+6=$ & 1 & $1 k+5=$ & 6 & Manik $+4=$ & 10 & Chuen \\
\hline
\end{tabular}

cuatro más, para completar un ciclo de 26 días $(26 \times 10=260)$. Imaginemos un típico almanaque maya completo, en el que los días parlantes son los que hemos venido señalando, pero que ocupan sólo parte del primer renglón (cuadro 7):38

Si un antiguo sacerdote maya hubiera de anotar ese ejemplo, lo podría hacer así:

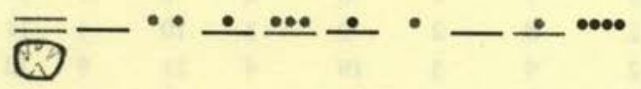

En otros términos, creo que puedo proponer que las fechas que conforman los distintos almanaques en los códices mayas son los días parlantes, es decir, aquellos que son significativos para el asunto que se trata de conocer, en relación con una pregunta concreta, un momento específico y un individuo particular.

En los ejemplos etnográficos, aunque el adivino conoce cuáles son los días parlantes, sólo puede integrar una lectura al tomar en cuenta tanto las características y condiciones del consultante, como el asunto que éste desea conocer. Estos elementos conforman la otra mitad que le permite al adivino realizar su tarea de manera cabal. ${ }^{39}$ La cuenta empieza, por ejemplo, el día en que se realiza la consulta para conocer la causa de una enfermedad, pero puede iniciarse también de acuerdo con el día en que el individuo enfermó. Entre los ixiles, una vez realizada una primera lectura, que permite diagnosticar una enfermedad, el sacerdote hace otra para determinar las acciones que el consultante deberá llevar a cabo con el fin de aplacar a los dioses que la han ocasionado.

Los adivinos actuales han conservado este calendario y con él han podido, según sus creencias, seguir en contacto con los dioses mayas. Quienes adivinan lo usan de una manera muy semejante a como lo hacían los sacerdotes prehispánicos, conservando en la disposición de las semillas y cristales la misma disposición general que se observa en los códices y reconociendo los días parlantes. Las diferencias formales entre el proceso adivinatorio están dadas por el uso de semillas y cristales para realizar la cuenta, en el caso de los sacerdotes contemporáneos, y por el uso de los antiguos códices por los chilames.

En cuanto al uso de semillas para realizar las cuentas de los días en los códices, en la página $8 \mathrm{~b}$ del Códice de Dresde se ve a un par de personajes posiblemente realizando esta acción. El dios $\mathrm{D}$, tanto por el dinamismo de su mano, como por la actitud corporal, parece estar dejando caer las semillas de su puño frente a otro dios que está sentado. Según Schele y Grube en el texto se alude a las semillas. ${ }^{40} \mathrm{Tal}$ vez aún las

\footnotetext{
${ }^{38}$ Para distinguir los días que presentan los Colby, los hemos maracado en negritas.

${ }^{39}$ Colby y Colby, El contador de los dias, pp. 241-242.

${ }^{40}$ Schele y Grube, Notebook for the Maya Hieroglyphic Forum, p. 104.

Estudios de Cultura Maya. Vol. XXI, 2000

Instituto de Investigaciones Filológicas/

Centro de Estudios Mayas, UNAM 
usan los contadores de los días para facilitar su tarea, a pesar de que carecen ya de códices.

En el caso de un almanaque jeroglífico, el sacerdote dispondría esquemáticamente los días utilizando seis columnas: la primera formada por dos filas paralelas de signos de días, la segunda que correspondería a los días que llevan el número 2 , la tercera a los que llevan el 8 , la cuarta a los que tienen el 1 , la quinta a los que tienen el 6 y finalmente la última equivale a los que tienen el número 10.

A través de la observación de la distribución del espacio en los códices mayas, resulta claro que el amanuense vinculaba las figuras de los personajes con las fechas. Esto nos permite decir que quienes están representados en los almanaques son los dioses que ejercen sus influencias sobre los distintos aspectos del mundo. Sin embargo, cabe preguntarse; ¿a cuál de las fechas se refiere cada personaje? En un almanaque $26 \times 10$, habría 10 fechas distintas en cada columna que tienen el mismo numeral; en uno de $52 \times 5$ serían cinco fechas que compartirian el numeral en las columnas, y en los almanaques de 65 dias, cuatro fechas, correspondientes a otras tantas columnas compartirían el mismo número. El sacerdote entonces tenía que realizar su augurio eligiendo alguna de estas opciones, y dando a conocer la voluntad divina. Pero ¿cómo lo hace?, ¿elige una de estas fechas en función del consultante?, ¿qué papel desempeñan el texto jeroglífico y las figuras dentro del almanaque?, ¿son siempre una unidad significativa?, ¿son el equivalente prehispánico de los recursos mnemotécnicos de que habla Tedlock que permiten comprender los augurios?, ¿por qué hay almanaques con figuras y sin texto?, ¿por qué no coinciden muchas veces los nombres jeroglíficos de los personajes con las figuras ahí representadas?

La gran cantidad de almanaques en el Códice Madrid que carecen de texto jeroglífico indica que el sacerdote podía realizar la lectura única- mente a través de las fechas abreviadas y las figuras. Un mismo amanuense realizó pasajes con glifos y sin glifos, lo que indica, a mi modo de ver, que la información pertinente la conocía de memoria el sacerdote, y que las figuras, pienso, eran un recurso mnemotécnico mediante el cual matizaba las diferentes valencias de los días. Así, resultaría inútil para el sacerdote leer el nombre glífico de una deidad, si era capaz de reconocerla con sólo mirarla. La gran cantidad de información que se podía añadir a cada figura mediante el atavío, el color, las posturas, los objetos y las acciones que realizaba eran el complemento ideal que le brindaba al sacerdote las pautas para una lectura precisa. Tal vez los almanaques que carecen de texto jeroglífico tienen un contenido diferente a los que sí presentan glifos. Como hipótesis inicial puedo sugerir la posibilidad de que sólo señalan las fechas de ciertas ceremonias relacionadas con el asunto que tratan y no se refieren a los augurios, o a la inversa, sólo contienen augurios y no registran ceremonias.

En algunos almanaques el nombre jeroglífico de ciertos personajes aparece sin que se le dibuje, situación que ha propiciado que algunos epigrafistas propongan que se trata de otro dios. Creo que en esos casos puedo proponer que en el texto se alude a dos dioses parlantes que actúan en distintos momentos: a uno se le representó mediante glifos y a otro mediante dibujos. El sacerdote dibujaba la figura del dios con ciertas características, lo que permitía reconocer el significado cabal del augurio, y anotaba mediante glifos el nombre y tal vez algunos atributos de otro dios, que actuaba en otra de las fechas. Cada uno tiene funciones y características especiales dentro de la lectura correspondiente.

Otro aspecto que hay que tomar en cuenta es que los sacerdotes actuales "leen" dos veces o más una misma disposición de días, con el fin de poder comprender cabalmente el designio 
divino y establecer el modo y el momento adecuados para comunicarse con los dioses mediante un ritual. Si en tiempos prehispánicos se manejaba así la adivinación, entonces en un mismo almanaque se podría aludir a dos aspectos diferentes y complementarios que el consultante debía conocer: por un lado, se determinarían, por ejemplo, las fechas propicias para iniciar la siembra, y, por otro, los rituales correspondientes para propiciar el buen éxito de ésta.

Tal vez la manera de iniciar la búsqueda de respuestas sería relacionar los distintos días de todos los almanaques con personajes concretos. Por ejemplo, cabría preguntarse ¿cuándo actúa el dios A? Entonces habría que buscar las fechas asociadas con las figuras de este dios y con los textos en los que aparece su nombre glífico. Esto nos permitiría conocer los momentos precisos en que, según el pensamiento maya, el dios está presente en el mundo, afecta diversos aspectos de la realidad, o requiere de culto.

Seguramente el estudio cuidadoso de los textos jeroglificos, así como una adecuada integración de la información plástica y calendárica, permitirá comprender mejor no sólo los sistemas mayas de adivinación, sino sobre todo a los hombres antiguos y modernos que han consultado durante más de 2000 años a los dioses que rigen las distintas fechas, pues los dioses mayas aún siguen hablando.

\section{Bibliografia}

Ayalı, MARicelA

1978 El año de 260 días en Mesoamérica, su origen y funcionamiento, tesis de licenciatura, unam, Facultad de Filosofia y Letras, Colegio de Historia, México.

Ciudad Real, Antonio de

1976 Tratado curioso y docto de las grandezas de la Nueva España. Relación breve y verdadera de algunas cosas de las muchas que sucedieron al padre fray Alonso Ponce en las Estudios de Cultura Maya. Vol. XXI, 2000

Instituto de Investigaciones Filológicas/

Centro de Estudios Mayas, UNAM

ISSN: 0185-2574 provincias de la Nueva España siendo comisario general de aquellas partes, edición Josefina García Quintana y Víctor M. Castillo Farreras, 2 vols., แн, UNAM, México (Serie de Historiadores y Cronistas de Indias, 6).

Codex Tro-Cortesianus

1967 (Codex Madrid), Museo de América Madrid, introducción y sumario de Ferdinand Anders, Akademische Druc-und Verlagsanstalt, Graz, Austria, (Códices Selecti Phototypice Impressi, vol. VIII).

1992 (facsimilar) introducción de Manuel Ballesteros Gaibrois, estudio crítico de Miguel Rivera Dorado, Ministerio de Cultura, Quinto Centenario, Testimonio, Compañía Editorial, Madrid.

Colby, Benjamin N., y Lore M. Colby

1986 El contador de los días. Vida y discurso de un adivino ixil, FCE, México.

Chevaluer, Jean, y Alain Gheerbrant

1988 Diccionario de los símbolos, Herder, Barcelona.

Diccionario maya Cordemex

1980 Alfredo Barrera Vásquez et al., Ediciones Cordemex, México.

Diccionario enciclopédico Espasa

199226 vols., Espasa-Calpe, Madrid.

El libro de los libros de Cbilam Balam

1978 traducción de sus textos paralelos por Alfredo Barrera Vásquez y Silvia Rendón, FCE, México (Colección Popular, 42).

ELANDE, MIRCEA

1975 Tratado de bistoria de las religiones, Ediciones Era, México.

1976 El chamanismo y las técnicas arcaicas del éxtasis, trad. Ernestina de Champourcin, FCE, México.

Forstemann, ERnST

1902 Commentary on the Madrid Maya Manuscript (Codex Tro-cortesianus), Horn, Danzig.

Garza, MERCEDES de LA

1990 Sueño y alucinación en el mundo nábuatl y maya, CEM-IIF, UNAM, México.

LA Farge II, Ouver, y Douglas Byers

1931 The Year Bearer's People, The Tulane University of Louisiana, Nueva Orleans (Middle American Research Series, Publication, 3).

LANDA, DIEGo DE

1973 Relación de las cosas de Yucatán, introd., de Ángel María Garibay, Editorial Porrúa, México. 
Lizana, BERnARdo dE

1995 Devocionario de Nuestra Señora de Izamal y conquista espiritual de Yucatán, edición crítica y anotada de René Acuña, CEM, IIf, unAm, México (Fuentes para el Estudio de la Cultura Maya, 12).

Los códices mayas

1985 introducción y bibliografia de Thomas A. Lee, Jr., Edición Conmemorativa X Aniversario, Universidad Autónoma de Chiapas, México.

Sánchez de Aguilar, Pedro

1951 "Informe contra idolorum cultores del obispado de Yucatán", en Tratado de las idolatrias, supersticiones, dioses, ritos, becbicerias $y$ otras costumbres gentilicas de las razas aborigenes de México, notas, comentarios y estudio de Francisco del Paso y Troncoso, Ediciones Fuente Cultura, México.
Schele, Linda, y Nikolai Grube,

1997 Noteboolk for the XXIst Maya Hieroglyphic Forum at Texas, The University of Texasat Austin.

Sotelo Santos, Laura Elena

"Los códices mayas", Arqueología Mexicana, México, vol. IV, núm. 23, pp. 34-42.

1997 Los dioses antropomorfos en el Códice Madrid, tesis de doctorado, Facultad de Filosofia y Letras, unam, México,

Tedock, Barbara Helen

1978 Quiché Maya Divination: a Theory of Practice, tesis de doctorado, University of Nueva York at Albany (copia de University Microfilms International, 1981).

Thompson, J. ERic S.

1971 Maya Hieroglypbic Writing, An introduction, University of Oklahoma Press, Norman.

1988 Un comentario al Códice de Dresde libro de jeroglificos mayas, trad. Jorge Ferrerio Santana, FCE, México. 